Proceedings of the 2011 Winter Simulation Conference

S. Jain, R.R. Creasey, J. Himmelspach, K.P. White, and M. Fu, eds.

\title{
THE MANAGED READINESS SIMULATOR: A FORCE READINESS MODEL
}

\author{
Christine Scales \\ Stephen Okazawa \\ Michael Ormrod \\ Defence Research and Development Canada \\ 101 Colonel By Drive \\ Ottawa, ON \\ K1A 0K2, CANADA
}

\begin{abstract}
This paper presents an overview of a force readiness simulation tool that has been developed for the $\mathrm{Ca}$ nadian Forces (CF). The Managed Readiness Simulator (MARS) is a versatile program that allows the user to quickly simulate a wide range of scenarios to forecast the extent to which the resources of an establishment are available to fulfill the requirements of a set of planned tasks over time. MARS can also account for the dynamics of the establishment, including recruitment, promotion, and attrition of personnel, and acquisition, maintenance and disposal of equipment. Two examples of how MARS has been applied to current CF problems are also included.
\end{abstract}

\section{INTRODUCTION}

In the context of this paper, force readiness refers to the availability of military resources to carry out a set of planned tasks. Resources refer to the personnel, equipment and facilities belonging to a military establishment and tasks represent the activities that occupy the time of these resources. Examples of tasks include training, equipment maintenance and missions. The Managed Readiness Simulator (MARS) is a versatile program that allows the user to quickly simulate a wide range of scenarios to forecast the extent to which the resources of an establishment are available to fulfill the requirements of a set of planned tasks over time. MARS can also account for the dynamics of the establishment, including recruitment, promotion and attrition of personnel, and acquisition, maintenance and disposal of equipment.

The software provides a graphical user interface that facilitates the creation and execution of simulation scenarios and the analysis of simulation output. The output analyzer allows the user to view aggregated simulation results and to drill down to view the status of specific tasks and units over time. This provides the user with a powerful tool to anticipate problems that may arise and to identify their cause. Ultimately, MARS is intended to provide critical information to senior military leadership. It provides them with forecasts of the impact of proposed changes to missions, the establishment, government policies, and other factors. A more detailed description of the motivation behind the development of MARS and its potential applications can be found in Ormrod, Young, and Pall (2007).

Several manpower simulation tools have been developed by various countries over the years. Military force planning simulation tools have been developed by Slovenia (Škulj, Vehovar, and Stamfelj 2008; Skraba et al. 2007), UK (Moffat 1992), Australia (Wang 2007), Belgium (Van Utterbeeck et al. 2009), for example. Some tools are quite specific, such as NetLogo (Wheeler 2005) that is used to simulate a United Nations (UN) peacekeeping operation under the threat of insurgent activity and provides optimal team sizes to maximize the survivability of the forces and to enhance force protection. The US Military has many specialized simulation tools (Murty et al. 1995; McGinnis and Fernandez-Gaucherand 1994; Thom- 
as et al. 1997; Miller K. 2009; Davenport et al. 2007; and Hutchins et al. 2005). Manpower planning in a business setting has also been explored by the University in Manchester in the UK (Gregoriades 2001), IBM (Lee 2007), and the Kennedy Space Center (Marin et al. 2006) among others.

Defence Research and Development Canada has developed several models as well. The Arena Career Modelling Environment (ACME) (Isbrandt and Zegers 2006) is a military career progression tool. The Production Management Tool (PMT) (Straver et al. 2009) models the training pipeline for specific military occupations. Tyche Fleet Mix Model (Eisler, Bourque, and Reive 2009) provides the most effective mix of maritime fleet assets to address multiple demand scenarios. MARS was designed to be a general purpose personnel, equipment and facility management model in that career progression and training can be incorporated into the model with deployments and other tasks performed by the resources. However, it is a forecasting tool instead of an optimizing tool, like Tyche.

This paper presents the design of the MARS model in Section 2 and the components of the software in Section 3. Sections 4 and 5 give examples of how MARS has been applied to military problems. Section 6 concludes by discussing the versatility of MARS.

\section{THE MARS MODEL}

The MARS model is designed to simulate a given Scenario by forecasting the ability of an Establishment to generate the Resources required to satisfy a set of Tasks occurring over time. The program also records the state of every Resource throughout the simulation; therefore the results can be used to determine the utilization level of a unit within the Establishment or of a specific group of Resources. The design of MARS is described in detail by Okazawa, Ormrod, and Young $(2009,2010)$.

The program models three types of Resources: Personnel, Equipment and Facilities. Every Resource occupies a Slot in an Organization as shown in Figure 1. The Attributes of the Resource must match the requirements of its Slot. For example a Slot may have the following requirements: rank $=$ Captain, and occupation = Infantry.

\section{Establishment Organizations}

Theatre Organizations

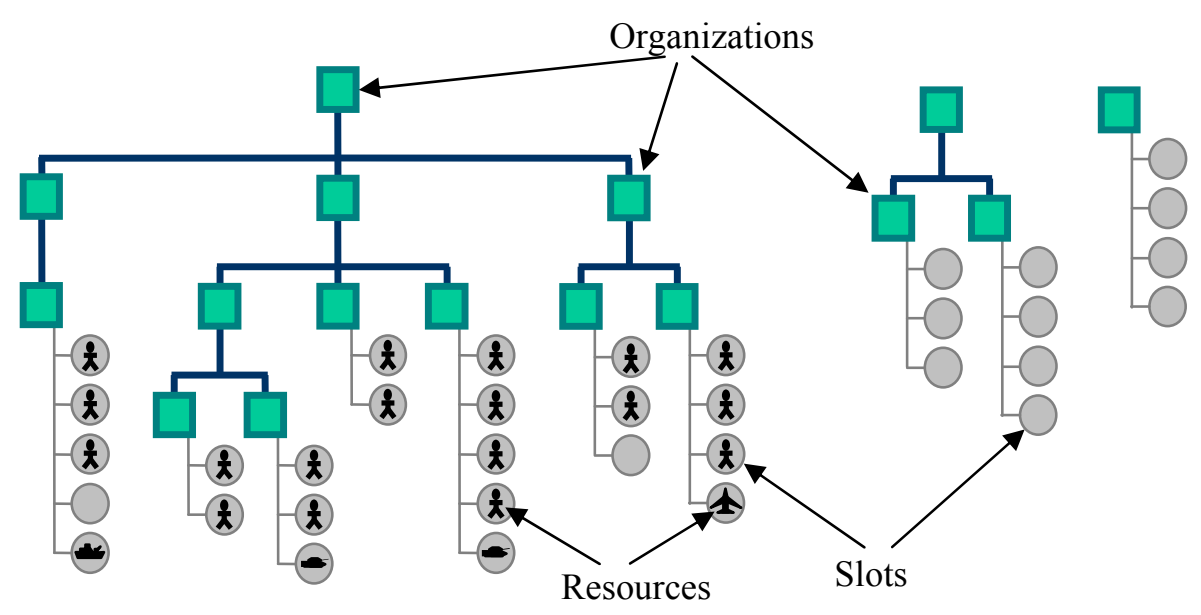

Figure 1: Establishment Organizations and Theatre Organizations showing Slots and Resources

An Organization consists of a group of Slots that define the Resource Requirements of a unit. They are typically arranged in a hierarchical tree structure where only the terminal nodes of the tree contain Slots. There are two types of Organizations. Establishment Organizations define the units that contain the Resources available in the Scenario. Theatre Organizations define templates of the units required by the Tasks during the simulation. During the simulation, the program fills these templates with Resources in order to perform a Task. 
Each Resource has Attributes that define its current state. Attributes store the information that determines whether a Resource can be chosen for a particular Task. Examples of Resource Attributes include a person's rank and qualifications. Other Attributes indicate whether the Resource is currently busy and whether there are any restrictions on what the Resource is allowed to do. In general, Attributes define the capability and availability of a Resource. These Attributes along with the Organization to which the Resource is attached are used to determine the eligibility of the Resource to fill a Slot in a Theatre unit required by a Task.

The operations and events being simulated in a MARS Scenario are represented by Tasks within the model. Each Task is broken down into Activities, which are scheduled within the Task so that they will occur with a specified timing. Activities are responsible for assembling the Resources they require. Activities can also be linked together to pass Resources directly from one Activity to another, and the commencing of an activity can be dependent on the completion of other activities. The Activity construct is illustrated below in Figure 2.

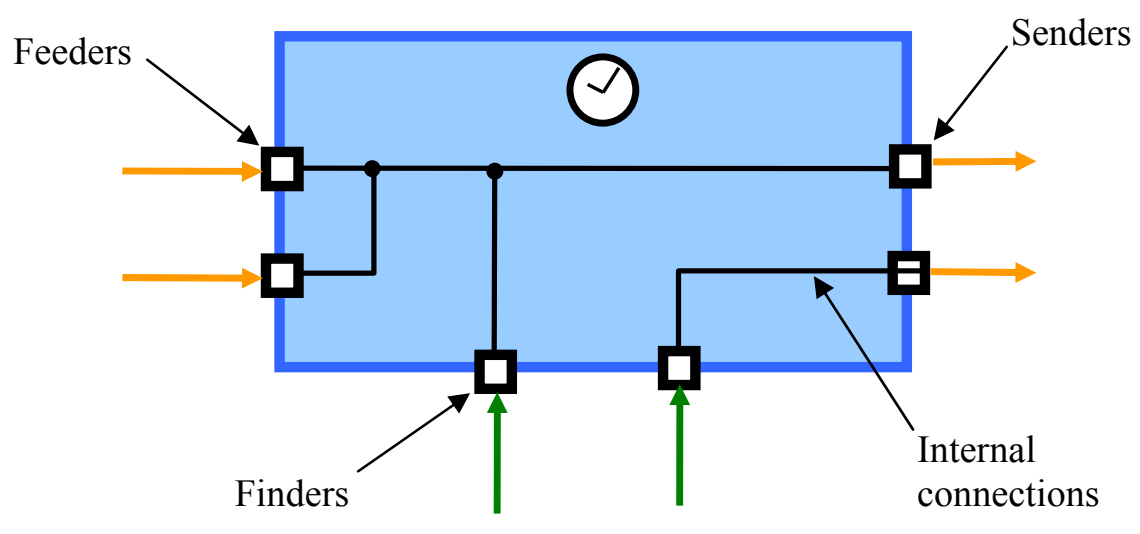

Figure 2: The Activity Construct showing Feeders, Finders and Senders and Internal Connections

Activities will run if and when they meet their specified resource, timing and dependency constraints. Resources enter an Activity as part of a Resource Group (ResGrp) through either a Feeder or Finder node and exit through a Sender node. An Activity may have multiple Feeders, Finders and Senders, but must have at least one Feeder or one Finder in order to employ Resources from at least one ResGrp. ResGrps are created by Finders which select Resources from the Establishment to participate in the Activity. A ResGrp is a set of Slots, where each Slot is occupied by at most one Resource selected to participate in the Activity.

Figure 3 illustrates the steps carried out by the Finders. First, the Finder identifies the Theatre Organizations that contain the Slots that define the Resource Requirement for the Activity. For example, a Disaster Assistance Response Team Triage Unit might contain Slots for a medical officer, a medical technician, and a nurse.

Next, the Finder specifies a prioritized list of Establishment Organizations that may be searched to find Resources to participate in the Activity. This prioritized list is subject to constraints that can be used to limit the number of Resources taken from a given Organization and to filter for Resources with certain Attributes. The Finder also verifies that these Resources have not already been assigned to a conflicting Activity. This produces a list of Candidate Resources.

The Finder then attempts to fill each Required Slot with one of the Candidate Resources by comparing the Attributes of the Resources to the requirements of each Slot. If a suitable match is found, the Resource is assigned to the Slot and becomes part of the ResGrp being created by the Finder. To maximize the number of successful matches, the Finder attempts to assign the least qualified Candidate that meets the requirements of each Slot. For example, a Slot that can be filled by either a Major or Lieutenant Colonel will be preferentially assigned a Major because Lieutenant Colonels, being of higher rank, are in 
shorter supply and may be required by other Slots with more stringent requirements. This process is repeated for all Finders, with each Finder creating a ResGrp.

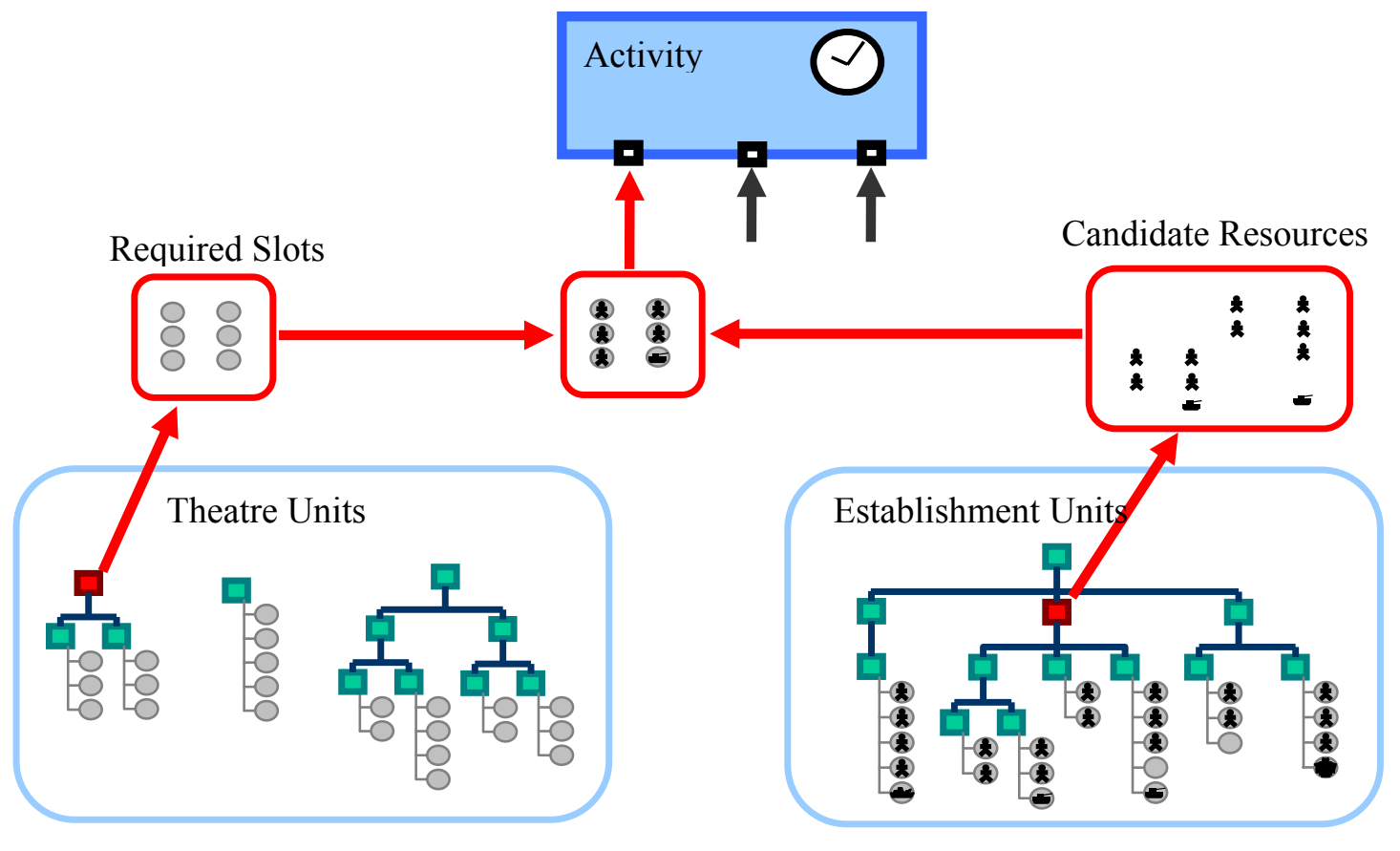

Figure 3: Resource Selection Process used by an Activity Finder.

Activities also acquire Resources through Feeders, which receive ResGrps that were created by a preceding Activity and passed on through one of that Activity's Senders. After acquiring its Resources through its Finders and Feeders, the Activity verifies that a specified minimum number of the required Slots have been filled. If this minimum requirement is not met, the Activity fails and the Resources are released. If sufficient Resources are found, the Activity takes control of the selected Resources, altering their Attributes to reflect the nature of the Activity and employing them for the duration of the Activity.

Each Feeder and Finder is connected internally to a Sender. Upon Activity completion, each ResGrp is passed to a Sender, which alters the Attributes of the Resources within the ResGrp to reflect the completion of the Activity. Each Sender is then responsible for either passing the ResGrps to the Feeder node of a follow-on Activity or for releasing the Resources within the ResGrp back to their Establishment unit. Senders and Feeders are the connection nodes that allow Activities to be linked together within a larger Task. When the Activity's processing time has finished and each ResGrp has exited through a Sender, the Activity is complete. Similarly, when all of the Activities of a Task are finished, the Task is complete.

To allow Tasks to be reused within a Scenario and to control when they begin, Task Generators are used to assign a start time to a Task. Multiple instances of a Task can be generated on a Rotation schedule to model the repetition of a Task such as a cycle of deployments that make up a continuous operation. When all of the Task Generators have been processed, and all of their associated Tasks are finished, the MARS Scenario is complete and the simulation stops.

From the outputs generated by the MARS simulation, the extent to which the Establishment was able to supply the Resources required for all the Tasks being modeled can be measured. More specifically, the output can be analyzed to determine how successful each Finder was in creating its ResGrp from the Establishment. By aggregating the results from the Finders, the user can determine how successful the Establishment was in generating the required Resources for each Activity, Task, Task Generator, and the entire Scenario. Similarly, the states of the Resources within the Establishment can be tracked over time. 
These results can be combined to plot the state of a particular Resource or group of Resources over time. A more detailed description of the outputs generated by MARS can be found in Okazawa and Ormrod (2011).

\section{MARS SOFTWARE COMPONENTS}

The MARS application consists of three major components, shown in Figure 4: a Scenario Database, a Managed Readiness Model, and a Graphical User Interface (GUI). The Scenario Database stores all the data that define a specific Scenario as well as the output generated during a simulation. The Managed Readiness Model is the discrete event representation of the process of selecting and employing Resources. The GUI allows the user to interact with the database and the model by performing three management functions. As the Input Manager, it is responsible for facilitating the input of Scenario data into the Scenario database. The input data consist of the Tasks, the Establishment, plans, and policies to be modeled in the proposed Scenario. The data may be input directly through the GUI input screens or imported from an external source such as a corporate database or spreadsheet. As the Simulation Manager, the GUI controls the execution of the Simulation Scenario. Finally, as the Output Manager, it allows a user to analyze the simulation results and to generate output reports. The red arrows in the Figure represent the data transfer between these components.

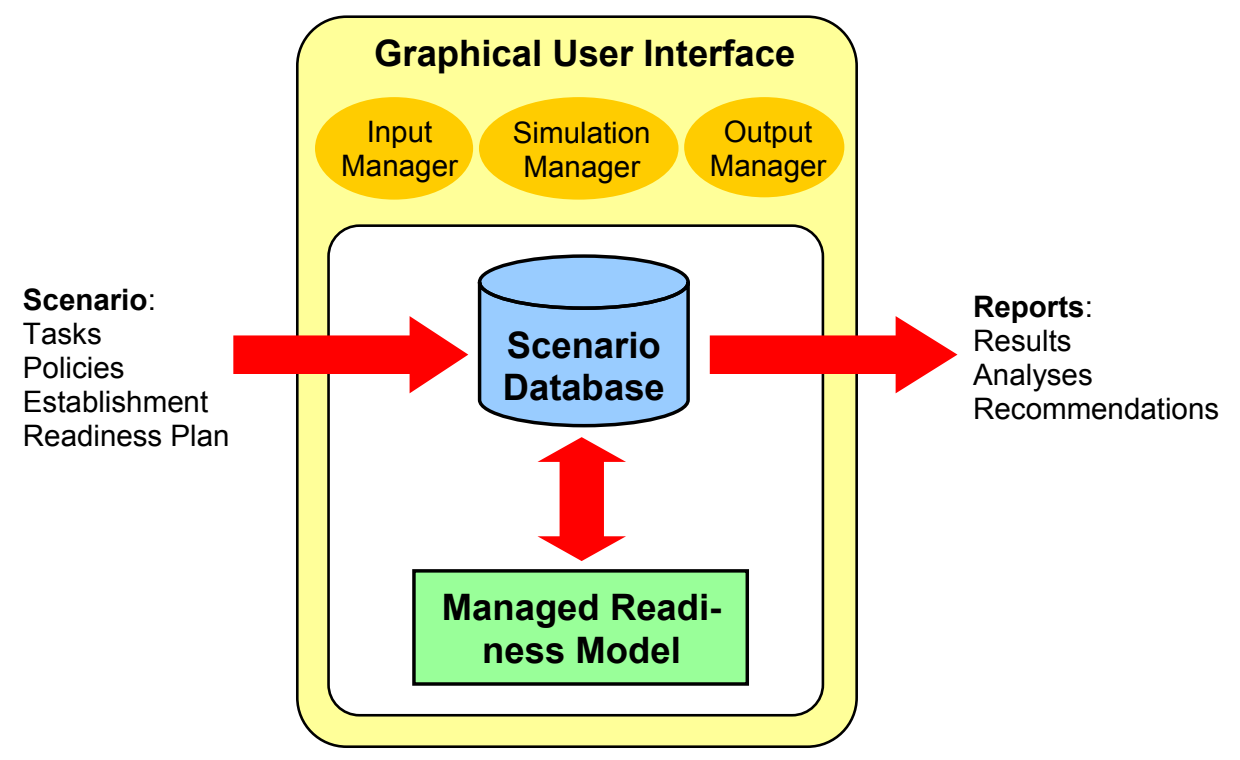

Figure 4: Components of the MARS application

\section{FORCE GENERATION APPLICATION EXAMPLE}

The Canadian Army is producing a reorientation plan to ensure it can fulfill its mandate post 2011 when it ceases combat operations in Afghanistan. The plan identifies the force elements required to carry out the missions defined by the Canada First Defence Strategy. MARS was used to analyze force structure options and how successfully the Brigade and Service Battalion in a Land Force Area (LFA) could simultaneously generate the required force elements.

The relative strength of the required force elements that were modeled in MARS as Tasks are shown in Table 1. Other tasks such as individual training and leave were modeled by randomly selecting $15 \%$ of the personnel resources from the LFA and removing them as candidates for the remaining missions/tasks. 
If a position required an individual from the Reserve Force or from other non-Brigade units not being modeled, the required individual was automatically generated by MARS.

The results from a typical MARS run for an LFA are shown in Figure 5. The purple at the bottom represents the personnel that were automatically created by MARS during the simulation. The large green bars represent the personnel that came from the unit given the primary force generation responsibility. The yellow bars represent positions that could not be filled by the primary unit but that were filled instead by personnel selected from another unit to augment the primary unit. Finally, the red bars on top represent the number of unfilled positions (slots).

Table 1: Force Generation Responsibilities of Each Force Area

\begin{tabular}{|l|l|l|}
\hline Task & Unit(s) & Personnel \\
\hline Major Sustained Operation (Major Op) & Battle Group & 1668 \\
\hline Minor Surge Operation (Minor Op) & Battalion Group & 689 \\
\hline Deployment of Strategic Reserve (Strat Res) & Infantry Company, Tank Squadron & 267 \\
\hline $\begin{array}{l}\text { Deployment of an Immediate Reaction Unit on } \\
\text { a Domestic Operation (IRU) }\end{array}$ & & 409 \\
\hline Battalion Support to Readiness Training (Sup) & & 450 \\
\hline
\end{tabular}

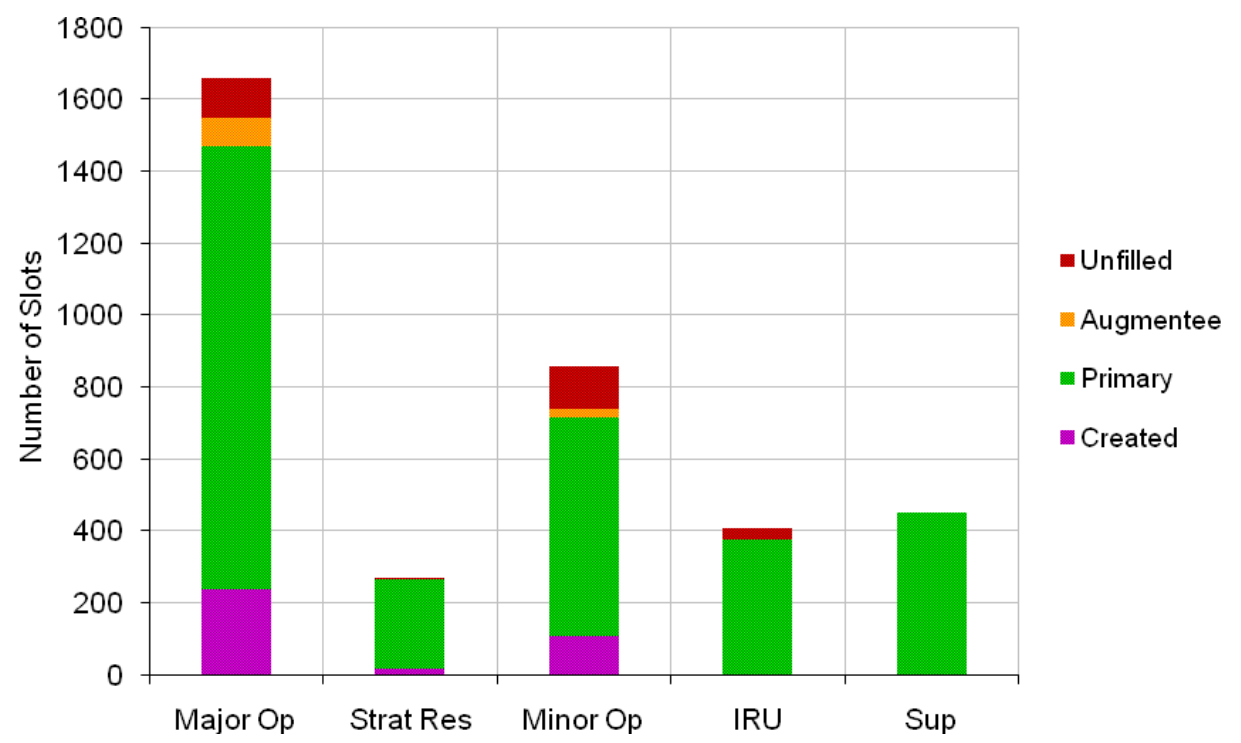

Figure 5: Canadian army reorientation results for the first rotation

The results identified force generation pressures for a Brigade and Service Battalion in an LFA as indicated by the unfilled positions in Figure 5. MARS was then used to determine which positions could not be filled in order to identify which military occupations were being stressed. The results for the unfilled positions for the Major Op were sorted and Table 2 lists those occupations by rank where there were a total of five or more unfilled positions. The table indicates that the unfilled positions predominantly require senior non-commissioned members from Combat Service Support trades. This allowed staff to further study areas of force generation pressure to refine options and develop necessary mitigation measures.

This MARS simulation provided the Canadian Army with detailed information on which aspects of planned operations are likely to encounter force generation problems. The analysis further indicated exactly which occupations are being stressed by excess demand. This information can then be used by military leadership to assess risks, revise mission planning and/or adjust force structure and training requirements. 
Table 2: Distribution of unfilled positions for major operation task with training support

\begin{tabular}{|l|c|c|c|c|c|c|c|c|}
\hline Occupation/Rank & $\begin{array}{l}\text { Corporal- } \\
\text { Private } \\
\text { (Trained) }\end{array}$ & Corporal & $\begin{array}{l}\text { Master } \\
\text { Corporal }\end{array}$ & Sergeant & $\begin{array}{l}\text { Warrant } \\
\text { Officer }\end{array}$ & $\begin{array}{l}\text { Master } \\
\text { Warrant } \\
\text { Officer }\end{array}$ & $\begin{array}{l}\text { Chief } \\
\text { Warrant } \\
\text { Officer }\end{array}$ & Total \\
\hline $\begin{array}{l}\text { Resource } \\
\text { Management } \\
\text { Support Clerk }\end{array}$ & 2 & 8 & 2 & 1 & 13 \\
\hline $\begin{array}{l}\text { Supply } \\
\text { Technician }\end{array}$ & 2 & 6 & 3 & & 2 & 1 & 12 \\
\hline $\begin{array}{l}\text { Intelligence } \\
\text { Operator }\end{array}$ & 4 & 3 & 2 & 1 & 1 & & 7 \\
\hline $\begin{array}{l}\text { Traffic } \\
\text { Technician }\end{array}$ & 2 & & & 1 & & & & 5 \\
\hline $\begin{array}{l}\text { Ammunition } \\
\text { Technician }\end{array}$ & 2 & & 3 & & & & & \\
\hline $\begin{array}{l}\text { Land Communica- } \\
\text { tions and Infor- } \\
\text { mation Systems } \\
\text { Technician }\end{array}$ & & & 3 & 1 & & 1 & & 5 \\
\hline Cook & 10 & 10 & 17 & 7 & 3 & 4 & 1 & 52 \\
\hline Total & & & & & & & \\
\hline
\end{tabular}

\section{PERSONNEL FLOW APPLICATION EXAMPLE}

The Army is in the process of restructuring the Signals Non-Commissioned Member occupations. The plan is to create a new Army Communication and Information Systems Specialist (ACISS) occupation by combining the current Land Communications and Information Systems Technician; Signal Operator; and Linemen occupations. This new structure is made up of a parent occupation and four sub-occupations. Three of the sub-occupations will contain specialized Technologists ranked from Corporal to Sergeant. They will be referred to as the Communication Systems Technologist (CST); Information Systems Technologist (IST); and Line Systems Technologist (LST). The fourth, a single capping sub-occupation ranked from Warrant Officer to Master Warrant Officer will be referred to as the Communication and Information Systems Technology Manager (CISTM). At the Chief Warrant Officer rank, the member will be employed in the parent occupation. The proposed new ACISS occupation structure is shown in Figure 6. Of the 3250 positions within the proposed structure, 700 are currently unfilled.

The successful implementation of the ACISS occupation structure is dependent on a number of critical factors. In order to validate the complex ACISS structure concept and to optimize the implementation and sustainment of this new occupation, MARS was used to conduct some population modeling analysis. The analysis is documented in Ormrod, Okazawa, and Scales (2011), and a brief summary is presented below.

The ACISS occupation structure was defined by building units for each of the different job groups shown in Figure 6. The ACISS occupation training courses were defined as a set of tasks with finders that selected eligible students and instructors from the resources within these units. After resources completed a course, their attributes were updated to reflect their new qualifications. A recruitment task created new personnel resources every year according to a specified intake plan. These new recruits were candidates for the first ACISS training course. Once they had completed this course, they became eligible for promotion into the ACISS structure. A promotion task identified empty slots within each rank, starting from the highest rank and matched them with resources in the rank below that met the promotion criteria and the slot requirements. Right before the promotion task was run, an attrition task randomly selected resources to be released based on historical attrition patterns. 


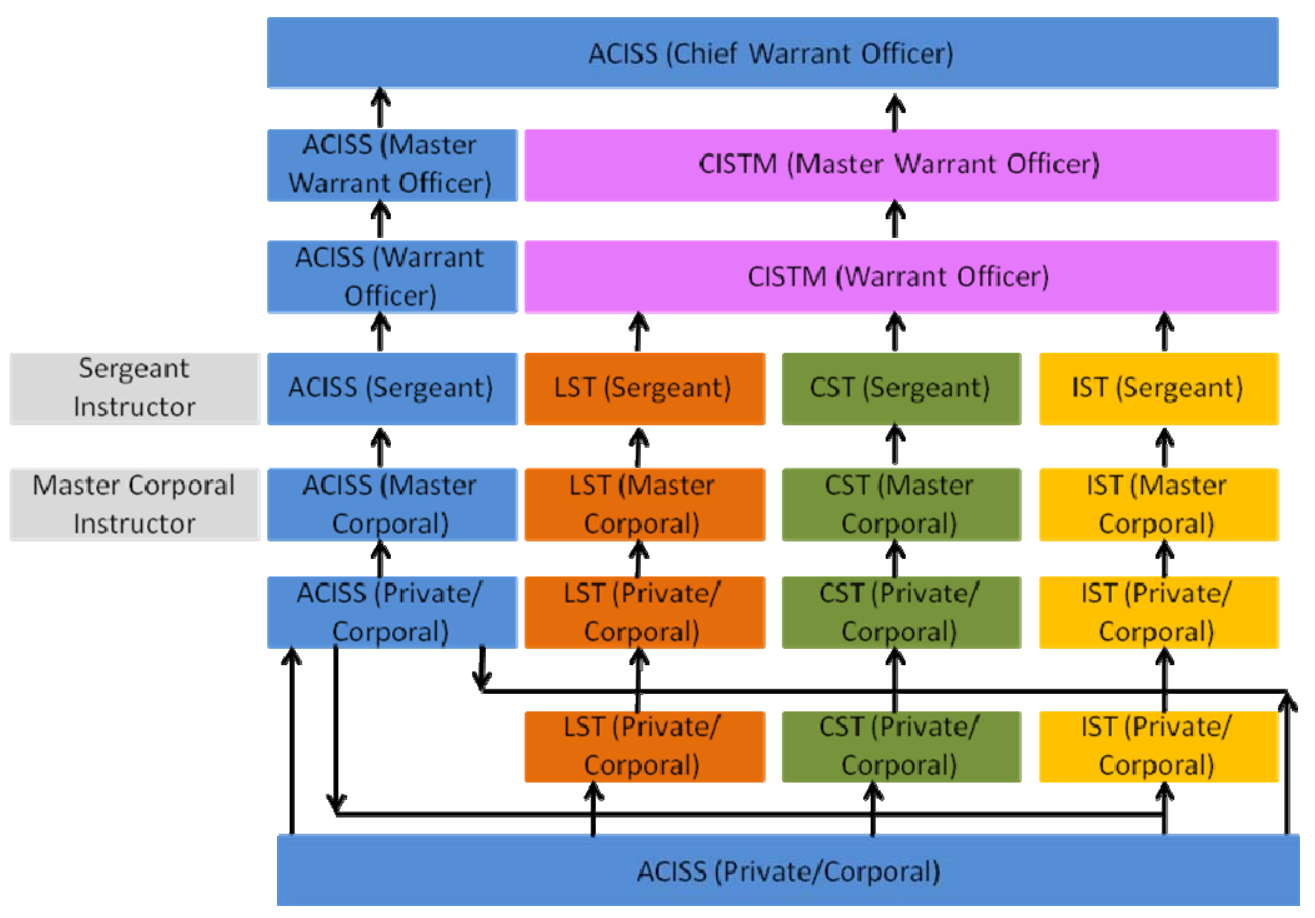

Figure 6: New ACISS occupation structure

The ACISS structure along with a proposed intake and training plan were successfully modeled in MARS for a 12-year period as shown in Figure 7. In general, the scenarios being analyzed are stochastic in nature due to the modeling of random events such as promotions, attrition, and training, which means the simulation results will differ between runs of the same scenario. Typically, one would conduct a Monte Carlo style simulation where many runs would be performed and statistically analyzed to determine the average or expected outcome as well as the range of potential outcomes. Although there were minor differences observed between the outputs from the runs, there was negligible impact on the occupation fillrate and bottleneck points; the same conclusions would be drawn from any of the simulation runs. Therefore, the typical statistical analysis was not performed. The results presented here are based on the output from one of the runs and can be assumed to be representative of the results of all the runs performed. The step-like results are due to the fact that the scenario was only modeling promotions and attrition on a three-month cycle. Preliminary results indicated that it would take approximately ten years to fill most (but not all) of the vacant positions in the new ACISS structure. By drilling down into the MARS results, it was determined that bottlenecks existed in the training system that limited the number of possible promotions. This affected the rate at which members moved between the ranks. The effect of these bottlenecks also prevented new recruits from being able to enter the ACISS structure as there were no entrylevel positions available, indicating that the proposed training plan was inadequate to support the proposed intake plan.

Proposals to address these bottlenecks were then examined by analyzing a second scenario in which the number of students allowed in specific courses was increased and some additional courses were run in the first year to model the effect of the proposed changes. With this adjusted training plan, MARS forecasted that the ACISS structure would be fully manned in approximately five years, shown in Figure 8, and that all new recruits would be able to find positions for the first three years. After this point, the planned intake exceeded the number of unfilled positions plus the expected attrition and therefore would have to be reduced. The result of these proposed changes was an ACISS structure that was filled in approximately half the time of the initial training proposal. Additional analysis would be required to opti- 
mize the intake proposals and to determine the number of training courses required to maintain the ACISS structure when it has reached a steady state condition.

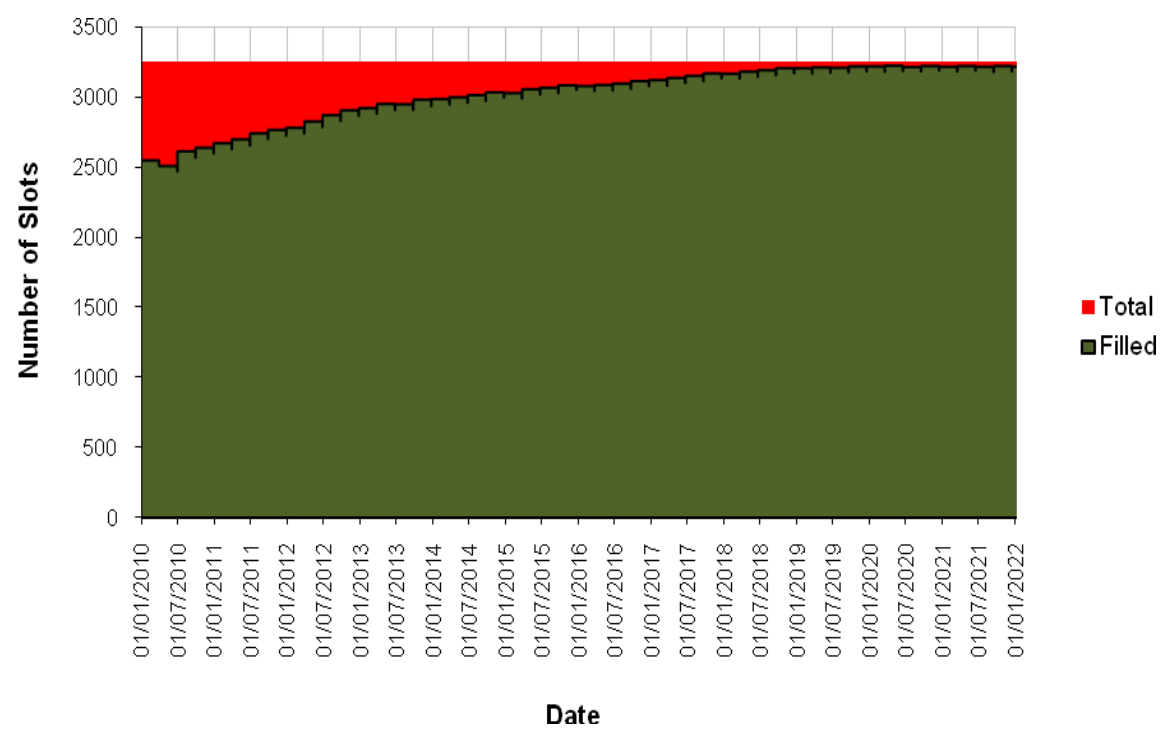

Figure 7: ACISS Slots filled in the proposed structure over 12 years

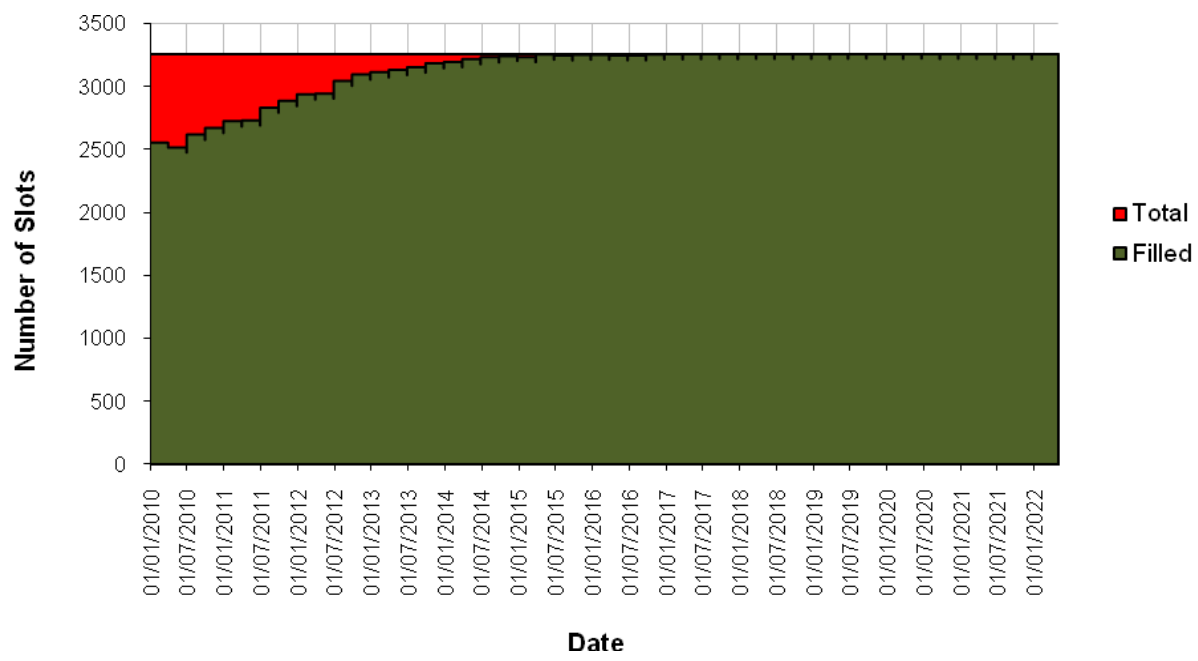

Figure 8: ACISS Slots filled over 12 years after proposed changes

This research provided the Canadian Army with a model of the proposed ACISS structure that can be expanded to forecast the effect of upcoming missions, updated attrition patterns, or proposed changes to the structure, training schedule, or intake plan. This model could also be used to examine other occupations.

\section{CONCLUSION}

This paper presented the MARS model, a simulation tool designed to assess the ability of a military Establishment to meet the demands of planned operations. The simulation model was described and examples of recent military applications were shown. In the first example, MARS was used to analyze part of 
the Army's Reorientation Plan and identified potential force generation problems. The results of this particular force structure option showed that the units within the brigade and service battalion of an LFA could not generate all of the personnel required to satisfy the proposed plan. In a second example, MARS was able to identify bottlenecks in a proposed plan to migrate several occupations to a new career structure. By simulating various scenarios, the MARS analysis produced recommendations on how to adjust the proposed training and intake plans to achieve the new career structure more efficiently and in half the time.

MARS is a versatile tool with many potential applications. Its strengths are its generic constructs that allow users to quickly simulate many force generation scenarios and its outputs that provide users with the ability to aggregate and drill down into the simulation results to identify the causes of a particular outcome. The ability to forecast how successfully an Establishment can generate the forces required to satisfy operational demands provides military decision makers with invaluable information that is otherwise unavailable.

\section{REFERENCES}

Davenport, J., C. Neu, W. Smith, and S. Heath. 2007. "Using Discrete Event Simulation to Examine Marine Training at the Marine Corps Communication Electronics School." In Proceedings of the 2007 Winter Simulation Conference, edited by S. G. Henderson, B. Biller, M.-H Hsieh, J. Shortle, J. D. Tew, and R. R. Barton, 1387-1394. Piscataway, New Jersey: Institute of Electrical and Electronics Engineers, Inc.

Eisler, C., A. Bourque, and W. Reive. 2009. "Fleet Mix Study: Capability Supply and Demand Requirements for Iteration II." Defence Research and Development Canada-Centre for Operational Research and Analysis (DRDC CORA), TM 2009-040. Ottawa, Canada.

Gregoriades, A. 2001. "Manpower Planning with System Dynamics and Business Objects." In Proceedings of International Systems Dynamics Conference, edited by J. H. Hines, V. G. Diker, R. S. Langer and J. I. Rowe, Atlanta, USA.

Hutchins, S. G., G. E. Schacher, J. Dailey, J. P. Looney, S. E. Saylor, J. J. Jensen, J. S. Osmundson, and S. P. Gallup. 2005. "Modeling and Simulation Support for the Standing Joint Force Headquarters Concept." In Proceedings of the 10th International Command and Control Research \& Technology Symposium.

Isbrandt, S., and A. Zegers. 2006. "The Arena Career Modelling Environment Individual Training and Education (ACME IT\&E) Projection Tool." Defence Research and Development Canada-Centre for Operational Research and Analysis (DRDC CORA), TR 2006-03. Ottawa, Canada.

Lee, Y. M. 2007. "Discrete Event Simulation Modeling of Resource Planning and Service Order Execution for Service Businesses." In Proceedings of the 2007 Winter Simulation Conference, edited by S. G. Henderson, B. Biller, M.-H Hsieh, J. Shortle, J. D. Tew, and R. R. Barton, 2227-2233. Piscataway, New Jersey: Institute of Electrical and Electronics Engineers, Inc.

Marin, M., Y. Zhu, P. T. Meade, M. Sargent, and J. Warren. 2006. "System Dynamics and Agent Based Simulations for Workforce Climate." In Proceedings of the 2006 Winter Simulation Conference, edited by L. R. Perrone, F. P. Wieland, J. Liu, B. G. Lawson, D. M. Nicol, and R. M. Fujimoto, 667-672. Piscataway, New Jersey: Institute of Electrical and Electronics Engineers, Inc.

McGinnis, M., and E. Fernandez-Gaucherand. 1994. "Resource Scheduling for the United States Army's Basic Combat Training Program." In Proceedings of the IEEE International Conference on Systems Man and Cybernetics, 553-558. San Antonio, Texas, USA: Institute of Electrical and Electronics Engineers, Inc.

Miller, K. 2009. "Overview of Modeling and Simulation in Support of the Active Army Military Manpower Program (AAMMP).” North Atlantic Treaty Organization. RTO-MP-SAS-073-09.

Moffat, J. 1992. "Three Case Studies of Operational Research for the Royal Air Force." Journal of the Operational Research Society 10:955-960. 
Murty, K.G., P. Djang, W. Butlerand, and R. Laferriere. 1995. “The Army Training Mix Model.” Journal of the Operational Research Society 3:294-303.

Okazawa, S., M. Ormrod, and C. Young. 2009. "Managed Readiness Simulator (MARS) V2: Design of the Managed Readiness Model.” DRDC CORA Technical Memorandum TM 2009-057.

Okazawa, S., M. Ormrod, and C. Young. 2010. "Managed Readiness Simulator (MARS) V2: Implementation of the Managed Readiness Model." DRDC CORA Technical Memorandum TM 2010-261.

Okazawa, S., and M. Ormrod. 2011. "Managed Readiness Simulator V2: The Graphical Simulation Output System.” DRDC CORA Technical Memorandum TM 2011-xx. (in press)

Ormrod, M., C. Young, and R. Pall. 2007. "Modelling Force Generation with the Managed Readiness Simulator (MARS): Modelling Concept and Requirements for MARS v1.0." DRDC CORA Technical Memorandum TM 2007-65.

Ormrod, M., S. Okazawa, and C. Scales. 2011. "Analysis of the Proposed Implementation of the New Army Communications and Information Systems Specialist (ACISS) Trade using the Managed Readiness Simulator (MARS).” DRDC CORA Technical Memorandum DRDC CORA TM 2011-xx. (in press)

Skraba, A., M. Kljajic, A. Knaflic, D. Kofjac, and I. Podbregar. 2007. "Development of a Human Resources Transition Simulation Model in Slovenian Armed Forces." In Proceedings of the Systems Dynamics Conference. Boston, USA: System Dynamics Society.

Škulj, D., V. Vehovar, and D. Štamfelj. 2008, "The Modelling of Manpower by Markov Chains - A Case Study of the Slovenian Armed Forces." Informatica 32:289-291.

Straver, M., S. Okazawa, A. Wind, and P. Moorhead. 2009. "Training Pipeline Modelling Using the Production Management Tool.” DGMPRA TM 2009-019. Director General Military Personnel Research and Analysis, Ottawa, Canada.

Thomas, D. A., B. T. Kwinn, M. McGinnis, B. A. Bowman, and M. D. Entner. 1997. "The US Army Enlisted Personnel System: a Systems Dynamics Approach." In Proceedings of the IEEE International Conference on Systems Man and Cybernetics, 1263-1367. Orlando, Florida, USA: Institute of Electrical and Electronics Engineers, Inc.

Wang, J. 2007. “A Systems Dynamics Simulation Model for a Four-Rank Military Workforce." Defence Science and Technology Organisation. DSTO-TR-2037.

Wheeler, S. 2005. "On the Suitability of NetLogo for the Modeling of Civilian Assistance and Guerilla Warfare." Defence Science and Technology Organisation. DSTO-TN-0623.

Van Utterbeeck, F., H. Pastijn, G. Van Acker, and R. Van Loock. 2009. "Computer Simulation and Markov Chain Modelling for HRM in the Belgian Defence." North Atlantic Treaty Organization. RTOMP-SAS-073-10.

\section{AUTHOR BIOGRAPHIES}

CHRISTINE SCALES is a Land Force Operational Research Defence Scientist at Defence Research and Development Canada - Centre for Operational Research and Analysis. She received her MASc in Electrical Engineering from the University of Ottawa. Her email is christine.scales@forces.gc.ca.

STEPHEN OKAZAWA is a Land Force Operational Research Defence Scientist at Defence Research and Development Canada - Centre for Operational Research and Analysis. He received his MEng in Electro-Mechanical Engineering from the University of British Columbia. His email is stephen.okazawa@forces.gc.ca.

MIKE ORMROD is the Land Force Operational Research Team Leader at Defence Research and Development Canada - Centre for Operational Research and Analysis. He received his MASc in Mechanical Engineering from University of Waterloo. His email is mike.ormrod@forces.gc.ca. 